\title{
Complicações protéticas na implantodontia: uma revisão de literatura
}

\section{Prosthetic complications in implantology: a literature review}

\section{Complicaciones protésicas en implantología: revisión de la literatura}

\author{
Alexandre Gomes de Siqueira ${ }^{1}$ \\ Eduardo Dias Ribeiro \\ Saulo Anderson Neves de Lima (iD \\ Amaro Lafayette Nobre Formiga Filho \\ Anne Helena Duarte de Aguiar ${ }^{2}$ \\ Josélia da Silva Leite ${ }^{3}$ \\ 1 ags_alexandre@hotmail.com \\ 2 annehelenaaguiar@gmail.com \\ 3 joseliadasilvaleite@gmail.com \\ Endereço para correspondência: \\ Alexandre Gomes de Siqueira \\ Rua Dr. João Pessoa, $353-1^{\circ}$. andar \\ 63101-075 - Crato - Ceará - Brasil \\ E-mail: ags_alexandre@hotmail.com
}

Recebido: 17.08 .2020

Aceito: 01.09.2020

\section{RESUMO}

A odontologia moderna está cada vez mais tecnológica e envolvida na interdisciplinaridade, a implantodontia não é diferente e anda a passos largos no avanço de suas técnicas e procedimentos, ao lado da prótese dentária vem alcançando novos patamares e possibilitando o tratamento reabilitador oral de cada vez mais pacientes, atualmente a maior parte dos casos de edentulismo podem ser tratadas por meio da instalação de implantes dentários, infelizmente alguns casos ainda encontram insucesso, e isso pode ser relacionado a diferentes processos, como problemas biomecânicos e biológicos dentre os quais podemos citar as fraturas, afrouxamentos e processos inflamatórios. Sabendo da importância do constante aprimoramento nas técnicas cirúrgicas e de instalação de peças protéticas o presente artigo tem por objetivo apresentar uma revisão de literatura sobre as complicações protéticas na implantodontia, de modo a prevenir a ocorrência desses problemas.

PALAVRAS-CHAVE: Odontologia. Implantes dentários. Prótese dentária.

\section{ABSTRACT}

Modern dentistry is more and more technological and involved in interdisciplinarity, implant dentistry is no different and is taking great strides in advancing its techniques and procedures, alongside dental prosthesis has been reaching new heights and 
enabling oral rehabilitation treatment more and more Currently, most edentulism cases can be treated by installing dental implants, unfortunately some cases are still unsuccessful, and this can be related to different processes, such as biomechanical and biological problems, among which we can mention fractures, loosening and inflammatory processes. Knowing the importance of constant improvement in surgical techniques and installation of prosthetic parts, this article aims to present a literature review on prosthetic complications in implant dentistry, in order to prevent the occurrence of these problems.

KEYWORDS: Dentistry. Dental implants. Dental prosthesis.

\section{RESUMEN}

La odontología moderna es cada vez más tecnológica e implicada en la interdisciplinariedad, la implantología no es diferente y está dando grandes pasos en el avance de sus técnicas y procedimientos, junto con la prótesis dental ha ido alcanzando nuevas alturas y permitiendo cada vez más el tratamiento de rehabilitación oral. Actualmente la mayoría de los casos de edentulismo se pueden tratar instalando implantes dentales, lamentablemente algunos casos aún no tienen éxito, y esto puede estar relacionado con diferentes procesos, como problemas biomecánicos y biológicos, entre los que podemos mencionar fracturas, procesos inflamatorios y de aflojamiento. Conociendo la importancia de la mejora constante en las técnicas quirúrgicas e instalación de piezas protésicas, este artículo tiene como objetivo presentar una revisión de la literatura sobre las complicaciones protésicas en implantología, con el fin de prevenir la aparición de estos problemas.

PALABRAS CLAVE: Odontología. Implantes dentales. Prótesis dental. 


\section{INTRODUÇÃO}

O edentulismo é um problema antigo e ainda muito presente na população brasileira, mesmo entre pessoas de diferentes classes sociais, especialmente as de mais idade ou de regiões mais carentes do país, onde o acesso a atendimento odontológico e ao conhecimento sobre técnicas de prevenção, tratamentos e importância da higiene oral básica ainda é muito precária seja por motivos econômicos, mas principalmente culturais ${ }^{1}$.

O profissional da odontologia se depara praticamente todos os dias com pacientes desdentados total ou parcialmente, de diferentes faixas etárias, e é papel fundamental da odontologia reabilitar esses pacientes, e a prótese dentária é a principal especialidade encarregada desses tratamentos a milhares de anos, atualmente existem diversas técnicas, materiais e procedimentos reabilitadores, cada um atendendo a necessidades e exigências diferentes ${ }^{2}$.

A prótese dentária é a especialidade odontológica responsável principalmente por reabilitar as funções estéticas e mastigatórias do sistema estomatognático, reestabelecer a melhor oclusão possível assim como a estética do sorriso seja pela reposição de elementos dentários perdidos, ausentes ou reparação de elementos gravemente danificados, para os casos de edentulismo parcial pode-se optar por próteses fixas ou removíveis, desde PPR's, Pontes fixas dento suportadas, ou mesmo implantossuportadas, assim como nos casos de perca de todos os elementos da arcada é possível se reabilitar o paciente por prótese total removível clássica ou por protocolos sobre implante.

$\mathrm{O}$ avanço dos tratamentos por implante vem sendo estrondoso nas últimas décadas, especialmente no que toca ao desenvolvimento de instrumentais, aprimoramento de técnicas cirúrgicas, desenvolvimento de materiais mais modernos, tratamento de superfícies, design dos implantes, utilização de bio materiais para regeneração óssea guiada e muito mais, tudo isso vem contribuindo para que a implantodontia moderna seja uma das áreas da odontologia com maior índice de sucesso nos tratamentos, com muitos estudos apontado para resultados de mais de $90 \%$ de sucesso nos implantes colocados ${ }^{1}$.

Contudo, como toda a técnica, a instalação de implantes também não é isenta de falhas e ainda são encontrados casos de perda ou desadaptação do implante em função de problemas relacionados com a biomecânica do conjunto prótese/implante, o implante dentário é apenas um componente do tratamento reabilitador como um todo, para que esse seja longevo é necessário que haja uma boa relação do implante com os tecidos peri-implantares para que se mantenham saudáveis além de uma boa distribuição das cargas oclusais sobre os implantes. Um desequilíbrio nas forças multidirecionais exercidas pela oclusão sobre o implante pode levar a complicações protéticas e mesmo a perda do implante dentário ${ }^{4}$.

Sabendo da importância de uma boa reabilitação protética para a alimentação, estética e mesmo autoestima do paciente, o presente trabalho apresenta uma revisão de literatura desenvolvida a partir de materiais de bases confiáveis, visando instruir a quem vier a conhece-lo sobre as melhores técnicas e os agentes causadores de problemas protéticos relacionados a implantes dentários evitando assim a ocorrência desses problemas ${ }^{2}$.

A presente revisão de literatura, desenvolvido de março a agosto de 2020 a partir de dados coletados em levantamentos literários de artigos, periódicos, livros e publicações digitais provenientes de bases de dados confiáveis, tais como Scielo, Bireme, BVS entre outros.

Dessas bases de dados foram obtidas várias publicações sobre os problemas protéticos associados a implantes dentários, os materiais foram buscados por meio de pesquisa pelas seguintes palavras-chave: descimentação, desadaptação, complicações protéticas, biomecânica, e de suas variáveis em inglês: resting, mismatch, prosthetic complications, biomechanics.

Partindo daí, foram reunidas as produções encontradas e dentro dessas foram feitas seleções seguindo os critérios de inclusão e exclusão, sendo selecionadas as publicações mais atualizadas e coerentes, com autores gabaritados e informações condizentes com o objetivo do estudo.

As informações então foram utilizadas para criação desse trabalho, que reuniu o que havia de melhor sobre o tema em um único documento.

\section{REVISÃO DE LITERATURA}

\section{Mecânica Oclusal}

Durante o processo mastigatório a maior parte das cargas oclusais é gerada durante a intercuspidação, uma vez que os elementos dentais pressionam o bolo alimentar entre si, em casos onde o processo de intercuspidação for instável, irá surgir uma má distribuição dessas cargas mastigatórias e isso induzirá o acúmulo repetitivo de tensões prejudiciais as estruturas, isso por sua vez, leva a sobrecarga em implantes dentários a região cervical, um do prejuízos causados por essa sobrecarga oclusal é a reabsorção óssea mais intensa. O implante é uma estrutura desprovida de ligamento periodontal de modo que não possui o amortecimento que a elasticidade do ligamento proporciona aos dentes, sendo assim a carga mastigatória é transmitida direto para o tecido ósseo, que acaba por desenvolver um processo mais acelerado de reabsorção ${ }^{1}$.

É importante que se considerem 3 fatores para a preservação contra a má distribuição de carga oclusal: a 
quantidade de implantes instalados no tratamento reabilitador deve estar em concordância com a topografia e a extensão da peça protética assegurando assim que haja um bom número de implantes para oferecer o suporte a mastigação. Um correto reestabelecimento da dimensão vertical de oclusão para assegurar uma mecânica mastigatória satisfatória; e um esquema oclusal satisfatório com registros precisos das relações maxilo-mandibuláres, esses cuidados devem ser tomados especialmente nas reabilitações posteriores e mais extensas, pois essas são as que mais recebem carga oclusal durante a mastigação ${ }^{3}$.

Estudos clínicos apontam que a realização de esplintagem das coroas protéticas de implantes que se encontram adjacentes tende a melhorar a distribuição de forças oclusais, não apenas na interface osso-implante, como também nos componentes protéticos propriamente ditos, a realização desse procedimento seria um benefício em especial para os pacientes com hábitos deletérios como o bruxismo lateral e horizontal, com baixa densidade óssea, portadores de enxertos ósseos e com ausência de guias de desoclusão ${ }^{5}$.

Devemos nos lembrar dos princípios de padrão oclusal implanto protegida, onde o arranjo oclusal visa aliviar a carga sobre os implantes o máximo possível, esse padrão oclusal é alcançado por algumas modificações durante a reabilitação, dentre elas podemos citar: uma mesa oclusal mais estreita, redução da inclinação das cúspides e um cantilever mais encurtado nas dimensões mesio-distal e buco-lingual ${ }^{1}$.

Dentre todos os princípios básicos da oclusão em relação a implantes dentários, podemos destacar como prioritários: a estabilidade bilateral durante a oclusão centrica habitual, contatos oclusais distribuídos com uniformidade, ausência de interferências entre a posição da centrica habitual e a posição de retrusão, movimentações amplas e com liberdade em oclusão centrica habitual, uma adequada guia anterior, quando possível, e movimentos laterais escursivos suaves e uniformes que não sofram interferências nos lados de trabalho ou de balanceio ${ }^{6}$.

\section{Complicações Biomecânicas das Próteses Implanto - Suportadas}

Podemos dividir as muitas possíveis complicações protéticas em implantes dentários em dois grandes grupos: os problemas por fatores biológicos e os problemas biomecânicos ${ }^{6}$.

Dentre os problemas biológicos destacam-se dois principais, a ausência ou pouca osseointegração do implante e a peri-implantite, ou seja, um processo inflamatório que dificulta a cicatrização, causado por uma contaminação microbiana da área peri-implantar, contaminação essa que se dá muitas vezes devido à má higiene bucal e ao acumulo de placa ou formação de tártaro, essa má higienização e proliferação bacteriana é potencializada quando ficam microespaços, gaps na junção do abutment com o implante ${ }^{3}$.
O tratamento odontológico para implantes infectados deve ser iniciado imediatamente após o diagnóstico, deve ser intenso e combinado com uma administração antibiótica local ou sistêmica e prolongada com debridamento cirúrgico devido à dificuldade em se conseguir erradicar colônias bacterianas das superfícies de biomateriais apenas com o uso de antibióticos .

Já no que se refere as complicações biomecânicas temos: a fratura do abutment protético, a fratura de parafusos, o afrouxamento do parafuso de fixação do abutment e de retenção protética a descimentação e a fratura do implante 6 .

\section{Fratura de Abutment Protético em Implantes}

Um dos principais problemas protéticos relacionados a implantes é a fratura de abutments, podendo acontecer esses problemas devido a processos relacionados a um afrouxamento prévio do parafuso não detectado ou pela associação de vários fatores como bruxismo, sobreestrutura desfavorável e/ou com adaptação não passiva, micromovimentos e sobrecarga entre outros ${ }^{7}$.

Ainda que um profissional experiente e bem treinado realize o encaixe preciso da armação e a realização de um cuidadoso ajuste oclusal, ainda podem ocorrer fraturas devido a uma espessura inadequada da estrutura metálica ou mesmo uma solda inadequada das juntas. Um abutment fraturado pode levar a uma leve mobilidade da ponte que acarretará subsequentemente a fratura do parafuso do abutment. Apesar da ser possível de se realizar a remoção do parafuso, nos casos de fratura de abutment é mais indicado é a colocação de uma nova estrutura. Um dos pontos que preveem a redução dessas ocorrências é a correta aplicação de torque com utilização de uma chave com um controle de torque o mais preciso possível ${ }^{3}$.

Uma fratura de abutment representa um alerta, que indica ao profissional que talvez seu procedimento tenha sido realizado com muita força durante a colocação ou que a carga em excesso esteja sendo aplicada sobre à prótese, isso evidencia que cuidados devem ser tomados, tais como a realização de ajuste oclusal por meio de redução da inclinação das cúspides, diminuição da largura vestíbulo-lingual e mesio-distal da prótese, eliminação dos contatos excursivos, obtenção de contatos oclusais centricos, adaptação passiva, diminuição do comprimento do cantilever, proteção contra bruxismo para os pacientes diagnosticados com hábitos deletérios, através de placas de mordida ou reconsiderações do plano de tratamento quanto ao tipo de prótese e o número de implantes que devem ser instalados ${ }^{6}$.

\section{Fratura de Parafusos}

Outro grave problema que pode ocorrer na implantodontia é a fratura do parafuso de retenção e de fixação (abutment). Ao se instalar implantes dentários, deve- 
se sempre observar como está a estabilidade da fixação do parafuso, especialmente em alguns fatores críticos: Aplicação adequada de pré-carga do parafuso, boa precisão da adaptação dos componentes de encaixe do implante, cuidado as características básicas de uma instalação e reabilitação que respeite e implante compensações antirotacionais da interface implante-abutment ${ }^{3}$.

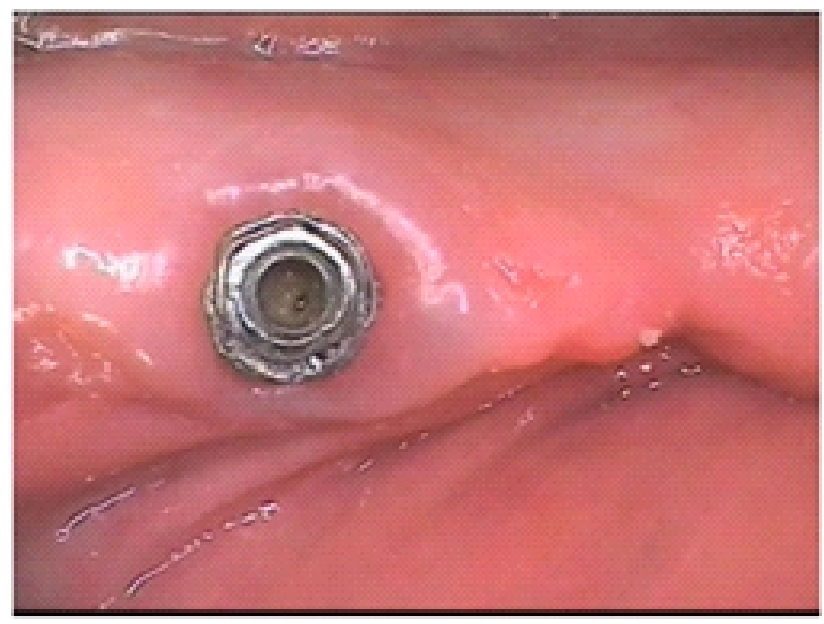

Figura 1 - Fratura do parafuso do pilar (visão intrabucal) ${ }^{8}$.

É sabido que uma pré-carga deve ser aplicada nos componentes protéticos pois, ela é útil para manter o implante e suas conexões em íntimo contato. Nesses casos, o termo apertamento reflete melhor essa situação clínica do que verdadeiramente uma carga. Os fatores biomecânicos tais como o tipo de conexão utilizada na reabilitação o torque empregado, a fadiga sofrida pelo metal, a existência de cantilever, o padrão da guia de desoclusão, a distribuição e inclinação dos implantes e tamanho da mesa oclusal estão todos relacionados ao sucesso da reabilitação, mas também com à maioria das causas das fraturas dos parafusos de fixação e retenção ${ }^{2}$.

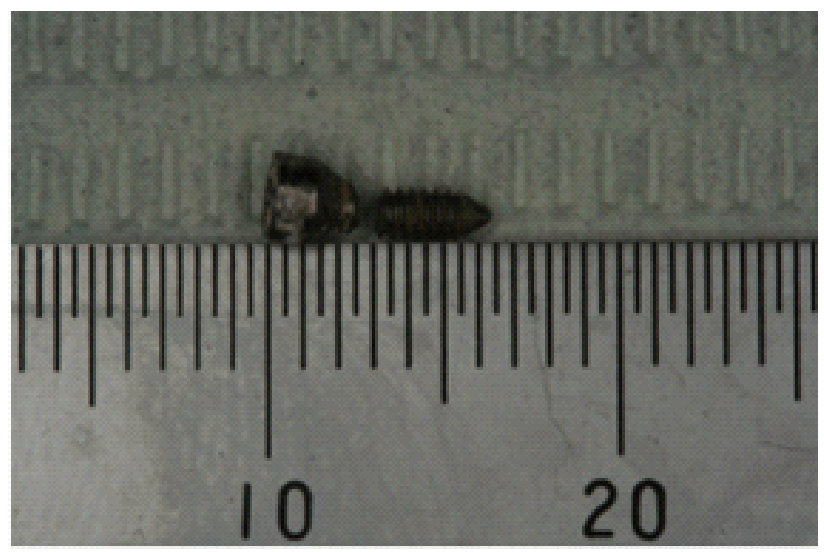

Figura 2 - Fratura do parafuso do pilar (após a remoção) ${ }^{8}$.
Quanto aos fatores fisiológicos, a presença de hábitos parafuncionais como o apertamento e o bruxismo e a sobrecarga funcional também são causas que contribuem para os casos de fratura dos parafusos, esses fatores podem agir isoladamente ou em conjunto, levando a um quadro que causa um afrouxamento do parafuso de retenção, ou fixação, e a sua posterior fratura ${ }^{9}$.

Um problema relacionado aos implantes que se observa com frequência é o afrouxamento dos parafusos de fixação e de retenção dos componentes dos implantes, e esse afrouxamento predispõe a fratura do parafuso ou do próprio implante, devendo o profissional sempre atentar para esses acontecimentos como um sinal de alerta que indica que o sistema de conexões necessita de avaliações periódicas. A principal razão para a fratura do parafuso é geralmente uma infraestrutura desfavorável, sobrecarga oclusal ou presença de hábitos deletérios. Existem vários fenômenos que compõem o fenômeno do afrouxamento dos parafusos, eles podem ocorrer em diferentes momentos, isolados ou em conjunto, o problema normalmente se inicia com um deslocamento, imperceptível clinicamente, seguido do seu estágio final onde ocorrerá vibração do parafuso, fazendo com que o mesmo gire em sentido contrário ao torque, aumentando desta forma, seu afrouxamento e o risco de fratura ${ }^{10}$.

\section{Afrouxamento de Parafusos}

As restaurações sobre implante osseointegrados, quando esses últimos se encontram em osso de boa qualidade, apresentam como ponto mais vulnerável o parafuso do abutment. A boa adaptação entre prótese e pilar protético e um apertamento eficiente do parafuso do abutment irão garantir a resistência da junta parafusada ${ }^{11}$.

Quando o parafuso do pilar protético é apertado, uma pré-carga é produzida, provocando tensão nos componentes que os faz ficarem unidos. Nos casos em que a adaptação é sofrível, a interface abutment-prótese faz apenas um contato parcial. Dessa forma, o parafuso acaba por receber toda a carga e a sua resistência à fadiga se torna reduzida. Quando uma carga externa é aplicada sobre os componentes que se encontram unidos, a tensão sobre o parafuso aumenta ainda mais. De acordo com os mesmos autores, nos casos em que a precisão da prótese é adequada, os parafusos oferecem uma resistência à fadiga por pelo menos um período de vinte anos. Nos casos em que a adaptação da prótese é deficiente, esse período de tempo é reduzido vertiginosamente ${ }^{2}$.

As deficiências de adaptação estão associadas às tensões na estrutura protética. Quanto maior a desadaptação, maior será a tensão e nos casos em que a discrepância de adaptação for excessiva, o parafuso não desenvolve força para unir a superestrutura à junta. Como a pré-carga se incumbe de unir as superfícies a perda desta faz 
com que o parafuso fique sujeito ao afrouxamento, à fadiga e à fratura ${ }^{9}$.

\section{Desadaptações}

Desadaptação é um processo de perca de estabilidade protética em função das tensões exercidas sobre a estrutura protética. Quanto maior for a desadaptação, maior será a tensão sofrida sobre as estruturas, e em casos em que a discrepância de adaptação for demasiadamente excessiva, $o$ parafuso não permitirá que a peça protética tenha estabilidade durante o processo mastigatório. A pré-carga responsável por unir os componentes ao implante perde forças e o parafuso fica sujeito ao afrouxamento, à fadiga e mesmo à fratura. A força de união é iniciada desde o momento em que a junta é montada e o parafuso apertado com um instrumento adequado ${ }^{7}$.

O aperto do parafuso por si só cria tensão no mesmo a medida que a cabeça do parafuso se encaixa no sitio do abutment $\mathrm{e}$ as espiras macho e fêmea se encaixam dentro do corpo do implante. Nesse processo de apertar o parafuso, o parafuso tende a se alongar e pressiona as duas partes entre si, criando uma força de união, a pré-carga ${ }^{2}$.

Por meio de estudos biomecânicos é possível demonstrar que mesmo as próteses parciais fixas que se encontram perfeitamente adaptadas causam um certo nível de estresse sobre as estruturas adjacentes. Isso, pois, ainda que nos casos em que as peças se apresentem com uma excelente adaptação ao exame clínico, as peças não deixam de ter inexatidões resultantes de processos de moldagem, de fundição da peça protética, tolerância mecânica e possíveis imprecisões dos processos laboratoriais. Assim como para as reabilitações com próteses cimentadas, presume-se que a camada de cimento é capaz de recobrir as superfícies e abrandar qualquer imprecisão, solucionando assim o problema da adaptação passiva, porém, ainda assim, existem muitos problemas relacionados a manipulação incorreta do cimento, a excesso de espessura e aplicação incorreta ou contaminada por humidade, o que enfraquece a união da peça com o pilar".

As próteses parciais fixas cimentadas apresentam níveis de estresse menores, quando as comparamos com as próteses fixas parafusadas, uma vez que o cimento adere por passividade, não necessita de apertamento do parafuso entre a peça e o implante, de modo que se fixa passivamente por meio do cimento ${ }^{10}$.

\section{Problemas Relacionados às Próteses Provisórias}

Durante um tratamento de reabilitação por implantes, existe inevitavelmente um espaço de tempo entre o planejamento e o resultado final, nesse meio tempo é necessário que os implantes tenham um bom processo de osseointegração, durante esse processo a peça deve descansar no tecido ósseo sem sofrer agressões, processos inflamatórios ou sobrecargas, caso isso ocorra, é possível que o processo não seja bem finalizado e os implantes se percam ${ }^{12}$.

Existem diferentes protocolos de colocação de implantes dentários, os mais tradicionais realizam cirurgias em dois momentos, instalando primeiramente os implantes, e reabrindo após um certo período de tempo, com protocolos mais modernos não realizando mais a reabertura, de qualquer maneira, nos protocolos onde o paciente necessita retornar futuramente para a colocação da prótese definitiva é fundamental que se reestabeleça adequadamente a estética e a função mastigatória do paciente nesse meio tempo da melhor maneira possível, uma das ferramentas mais utilizadas são as próteses provisórias ${ }^{11}$.

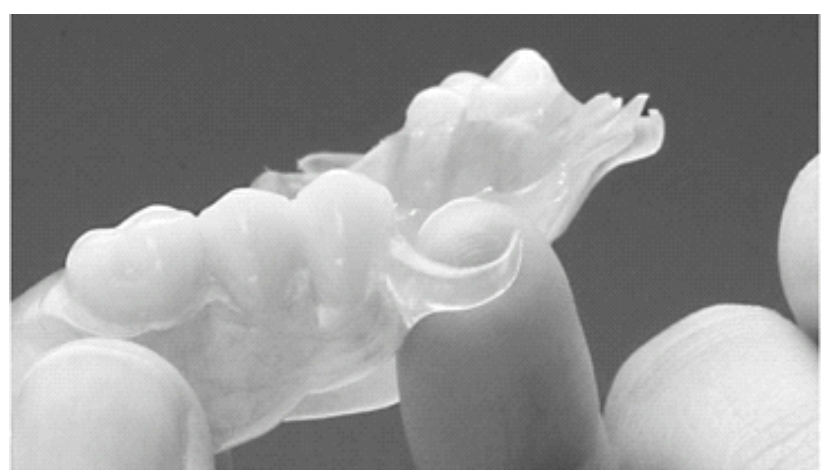

Figura 3 - Prótese provisória do tipo flexível ${ }^{11}$.

Essas peças são confeccionadas geralmente em acrílico termo ou quimicamente ativada ou mesmo flexíveis confeccionadas por injeção, essas peças são confeccionadas em laboratório e devem se adaptar na cavidade bucal do paciente para que ele tenha estética e função mastigatória já durante o pós operatório até a colocação final das próteses sobre implante, uma peça ideal, deve reabilitar o paciente da melhor maneira possível, mas com igual importância não pode sob hipótese alguma prejudicar a osseointegração dos implantes ou a cicatrização da cirurgia ${ }^{8}$.

As próteses provisórias devem ser confeccionadas com qualidade, bem adaptadas e confortáveis, geralmente são re-embasadas com resina soft ou algum outro tipo de material que assegure a sua adaptação na cavidade bucal, de modo que fique bem ajustada e não cause sobrecarga nos implantes, quando isso ocorre, por um defeito de confecção ou por um manejo incorreto por parte do profissional ou paciente, a prótese pode causar uma pressão excessiva sobre implante ou sobre o tecido gengival, nesses casos pode ocorrer processos inflamatórios que prejudicam o pós cirúrgico, ou então pode ocorrer também uma sobrecarga nos implantes, a junção desses dois fatores prejudica diretamente o processo de osseointegração que não se desenvolve bem com cargas excessivas e processos inflamatórios, quando esse quadro se prolonga por muito tempo sem correção, pode ocorrer mesmo a perca dos 
implantes que não osseointegram e não estão firmes no momento da reabertura, levando o profissional a perder o tempo de tratamento, a peça protética e ter que realizar todo o retrabalho de reabilitação, o que é uma situação muito negativa para o profissional e para o paciente ${ }^{12}$.

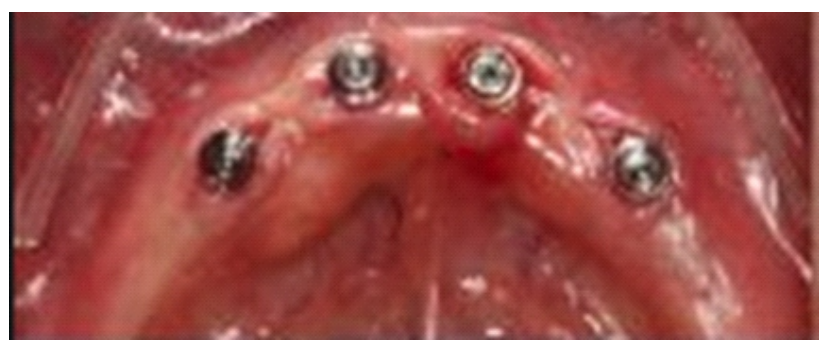

Figura 4 - Processo inflamatório ao redor de cicatrizadores devido a prótese provisória mal adaptada ${ }^{11}$.

É fundamental que se conduza corretamente o póscirúrgico em reabilitações orais por implante, com o mesmo critério e cuidados que se conduz o processo de implantação em si, as próteses provisórias devem ser bem planejadas, bem confeccionadas e ajustadas ao máximo, com eliminação e todos os contatos prematuros, áreas excessivamente retentivas ou compressivas, além de serem re-embasadas e ajustadas a cada consulta de retorno durante todo o acompanhamento do paciente ${ }^{2}$.

\section{DISCUSSÃO}

As tentativas de reposição de elementos dentários perdidos remetem aos primórdios da humanidade. Por séculos os seres humanos buscaram ainda que de maneira empírica, alcançar a reabilitação de elementos perdidos, seja por estética ou função, passaram-se os anos e a odontologia se incorporou cada vez mais aos processos tecnológicos e científicos, no século $\mathrm{XX}$ veio a descoberta do fenômeno da osseointegração por Branemark, e isso trouxe uma nova era para os tratamentos de reabilitação oral, desenvolveram-se procedimentos com alta previsibilidade e eficácia, estética e bom prognóstico. Atualmente os tratamentos por implantes são usados em larga escala no mundo todo e com índices elevados de sucesso e aceitação pelos pacientes, uma leva cada vez maior de profissionais está habilitada a realiza-los cada vez com um custo menor e mais acessível a diversos pacientes ${ }^{11}$.

As constantes evoluções nas técnicas cirúrgicas, tecnologia de materiais e tratamento de superfícies, além da regeneração óssea guiada, a osseointegração vem sendo cada vez mais rápida e eficiente, isso vem trazendo mudanças significativas na obtenção de uma boa interface osso-implante, tais evoluções permitiram aos estudiosos e fabricantes conseguirem a otimização do desenho dos implantes, sua superfície e composição química como formas de se influenciar as respostas celulares e teciduais em torno do implante ${ }^{13}$.

Muitos avanços foram alcançados com o decorrer dos estudos sobre o desenvolvimento de novos conceitos, metais e técnicas que possibilitaram a realização de reabilitações protéticas por implantes que eram bem mais adaptadas para enfrentar a mecânica oclusal, agindo mais próximo de próteses dento-suportadas ${ }^{2}$.

Contudo, estudos e acompanhamentos clínicos são sempre necessários para aprimorar o atendimento clínico, pois, mesmo com todo esse avanço ainda ocorrem problemas nas reabilitações por implante, e com isso alguns casos ainda que poucos, terminam em insucesso, seja por fraturas, desadaptações, contaminações ou outras ocorrências, dessa maneira é fundamental que se faça o constante acompanhamento para uma melhor prática clínica ${ }^{5}$.

Dentre as principais complicações das próteses implanto suportadas, existem dois grupos principais, os biológicos e biomecânicos. Com os fatores biológicos sendo mais relacionados as condições de assepsia do procedimento cirúrgico, falta de conservação por parte do paciente ou de pouca higienização por descuido ou dificuldade de acesso, todos os casos têm em comum a proliferação de agentes microbianos que causam inflamação dos tecidos e perda de integração óssea. Já os fatores biomecânicos são relacionados principalmente a instalação inadequada dos componentes, desadaptação das próteses, má distribuição das cargas oclusais, hábitos deletérios por parte do paciente, defeitos na confecção ou associação de vários desses fatores ${ }^{9}$.

\section{CONCLUSÃO}

A implantodontia é uma das áreas mais bem sucedidas da odontologia, com uma das maiores diversidades no que tange a materiais utilizados, dispositivos, equipamentos, técnicas cirúrgicas, casos possíveis de tratar, associação com outras áreas e sucesso nos casos, porém, ainda que com taxas atuais de sucesso demais de $90 \%$, a implantodontia não está imune a falhas, tratamentos mal sucedidos ou repetições de procedimentos, sendo assim é indispensável que se mantenha o constante cuidado e aprimoramento das técnicas.

A prótese dentária é o braço direito da implantodontia, as duas especialidades caminham juntas, uma vez que a colocação de implantes osseointegrados por si só não constitui reabilitação alguma, uma vez que os implantes não permitem reabilitação estética e muito menos funcional sozinhos, eles necessitam de próteses dentárias, sejam elas unitárias, parciais ou completas, e essas próteses por sua vez, em muitos casos não são capazes de encontrar sustentação na cavidade bucal para realizar suas funções 
com a qualidade exigida, motivo pelo qual recorrem a associação com implantes dentários para assegurar a máxima reabilitação estético-funcional possível, daí surge e ideia das próteses dentárias sobre implantes.

Podemos citar como principais problemas protéticos associados a implantes dentários, a peri-implantite causada quando o paciente tem descuido ou impossibilidade de higienizar adequadamente a região do implante dentário, de modo que os microrganismos se acumulam junto ao biofilme dentário e causam um processo inflamatório que impossibilita a correta adesão entre a superfície do implante e o tecido ósseo, o afrouxamento dos parafusos entre a prótese e os implantes que dificultam a estabilidade durante a oclusão, a fratura dos parafusos ou abutments, e a fratura da prótese em si, todos esses problemas são relacionados a sobrecarga oclusal, excesso de força durante a instalação dos parafusos e desajuste oclusal.

Outro fator preocupante e não diretamente associado à colocação dos implantes, são as próteses provisórias, que caso não estejam devidamente ajustadas e adaptadas podem acabar por atrapalhar e mesmo levar ao fracasso de tratamentos de implantes bem planejados e executados, mas que não irão integrar corretamente devido à sobrecarga causada por uma prótese provisória desajustada.

O correto entendimento dos protocolos de instalação protética sobre implantes, assim como os protocolos cirúrgicos para instalação dos implantes é fundamental para o sucesso do tratamento, assim como um bom planejamento protético que leve em consideração o padrão oclusal ideal e a boa distribuição das cargas, com isso será possível uma boa reabilitação protética sobre implantes.

\section{REFERÊNCIAS}

1. Degidi M. Immediately loaded short implants: analysis of a case series of 133 implants. Quintessence Int. 2007;38(3):193-201.

2. Zavanelli R. Guilherme A, Castro A. Fatores locais e sistêmicos relacionados aos pacientes que podem afetar a osseointegração. RGO. 2011;59(Supl 0):133-46.

3. Yamamoto M, Ogawa T, Yokoyama M, Koyama S, Sasaki K. Influence of immediate and early loading on bone metabolic activity around dental implants in rat tibiae. Clin Oral Implants Res. 2013;25(9):1084-90.

4. Santos P, Julia L, Millena F, Islayne C, Natália K. Desempenho dos implantes curtos na odontologia reabilitadora. Rev ACBO. 2017;26(2):65-72

5. Romeo E, Tomasi C, Finini I, Casentini P, Lops D. Implant-supported fixed cantilever prosthesis in partially edentulous jaws: a cohort prospective study. Clin Oral Implants Res. 2009;20(11):1278-85.

6. Gallucci G, Morton D, Weber H. Loading protocols for dental implants in edentulous patients. Int J Oral Maxillofac Implants. 2009;24(Suppl):132-46.
7. Gallucci G, Doughtie C, Hwang J, Fiorellini J, Weber H. Five-year results of fixed implant-supported rehabilitations with distal cantilevers for the edentulous mandible. Clin Oral Implants Res. 2010;20(6):601-7.

8. Santos V, Trento C, Santos P, Siqueira A, Santos S, Griza S. Análise da resistência à fratura entre pilares retos e angulados do sistema cone Morse. Rev Odontol UNESP. 2015;44(2):67-73.

9. Weber H, Morton D, Gallucci O, Roccuzzo M, Cordaro L, Gru?tter L. Consensus statements and recommended clinical procedures regarding loading protocols. Int J Oral Maxillofac Implants. 2009;24(Suppl):180-3.

10. Stevenson GC, Riano PC, Moretti AJ, Nichols CM, Engelmeier RL, Flaitz CM. Short term success of osseointegrated dental implants in HIV positive individuals: a prospective study. J Contemp Dent Pract. 2007;8(1):1-10.

11. Pereira M, Prótese protocolo sobre implantes: complicações e soluções envolvendo cantilevers. Rev Catarinense Implantodontia. 2014;14(16):18-22.

12. Coppedê AR, Mattos MG, Rodrigues RC, Ribeiro RF. Effect of repeated torque/mechanical loading cycles on two different abutment types in implants with internal tapered connections: an in vitro study. Clin Oral Implants Res. 2016;20(6):624-32.

13. Toledo F. Avaliação do destorque de dois tipos de parafusos fixadores do munhão e da resistência à tração de coroas cimentadas sobre munhões com diferentes características superficiais [thesis]. Bauru (SP): Universidade de São Paulo; 2011. 